\title{
The role of obesity in the biomechanics and radiological changes of the spine: an in vitro study
}

\author{
Nestor G. Rodriguez-Martinez, MD, ${ }^{1}$ Luis Perez-Orribo, MD, PhD, ${ }^{1}$ Samuel Kalb, MD, ${ }^{1}$ \\ Phillip M. Reyes, BSE, ${ }^{1}$ Anna G. U. S. Newcomb, MS, ${ }^{1}$ Jeremy Hughes, MD, ${ }^{2}$ \\ Nicholas Theodore, MD, ${ }^{1}$ and Neil R. Crawford, PhD'
}

Divisions of ${ }^{1}$ Neurological Surgery and ${ }^{2}$ Neuroradiology, Barrow Neurological Institute, St. Joseph's Hospital and Medical Center, Phoenix, Arizona

OBJECT The effects of obesity on lumbar biomechanics are not fully understood. The aims of this study were to analyze the biomechanical differences between cadaveric L4-5 lumbar spine segments from a large group of nonobese (body mass index $[\mathrm{BMI}]<30 \mathrm{~kg} / \mathrm{m}^{2}$ ) and obese $\left(\mathrm{BMl} \geq 30 \mathrm{~kg} / \mathrm{m}^{2}\right.$ ) donors and to determine if there were any radiological differences between spines from nonobese and obese donors using MR imaging.

METHODS A total of 168 intact L4-5 spinal segments ( 87 males and 81 females) were tested using pure-moment loading, simulating flexion-extension, lateral bending, and axial rotation. Axial compression tests were performed on 38 of the specimens. Sex, age, and BMI were analyzed with biomechanical parameters using 1-way ANOVA, Pearson correlation, and multiple regression analyses. MR images were obtained in 12 specimens ( 8 from obese and 4 from nonobese donors) using a 3-T MR scanner.

RESULTS The segments from the obese male group allowed significantly greater range of motion (ROM) than those from the nonobese male group during axial rotation $(p=0.018)$, while there was no difference between segments from obese and nonobese females $(p=0.687$ ). There were no differences in ROM between spines from obese and nonobese donors during flexion-extension or lateral bending for either sex. In the nonobese population, the ROM during axial rotation was significantly greater for females than for males $(p=0.009)$. There was no significant difference between sexes in the obese population ( $p=0.892$ ). Axial compressive stiffness was significantly greater for the obese than the nonobese population for both the female-only group and the entire study group $(p<0.01)$; however, the difference was nonsignificant in the male population $(p=0.304)$. Correlation analysis confirmed a significant negative correlation between BMI and resistance to deformation during axial compression in the female group $(R=-0.65, p=0.004)$, with no relationship in the male group $(R=0.03, p=0.9)$. There was also a significant negative correlation between $R O M$ during flexion-extension and BMI for the female group $(R=-0.38, p=0.001)$, with no relationship for the male group $(R=0.06$, $p=0.58)$. Qualitative analysis using MR imaging indicated greater facet degeneration and a greater incidence of disc herniations in the obese group than in the control group.

CONCLUSIONS Based on flexibility and compression tests, lumbar spinal segments from obese versus nonobese donors seem to behave differently, biomechanically, during axial rotation and compression. The differences are more pronounced in women. MR imaging suggests that these differences may be due to greater facet degeneration and an increased amount of disc herniation in the spines from obese individuals.

http://thejns.org/doi/abs/10.3171/2015.7.SPINE141306

KEY WORDS lumbar spine; biomechanics; obesity; flexibility

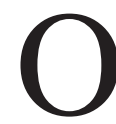
VERWEIGHT and obese are defined as abnormal or excessive fat accumulation that may impair overall health. The WHO defines a person as overweight if his or her body mass index (BMI, calculated as $\left.\mathrm{kg} / \mathrm{m}^{2}\right)$ is $\geq 25$ and $<30$. Individuals with a BMI $\geq 30$ are considered obese, and individuals with a BMI $\geq 40$ are considered morbidly obese. As recently as 2008 , the WHO estimated that 1.5 billion adults 20 years or older were overweight. ${ }^{38}$ Of these, approximately 200 million men and 300 million women were obese. In 2010, the

ABBREVIATIONS BMD = bone mineral density; $\mathrm{BMI}=$ body mass index; $\mathrm{ROM}=$ range of motion .

SUBMITTED December 22, 2014. ACCEPTED July 23, 2015.

INCLUDE WHEN CITING Published online December 11, 2015; DOI: 10.3171/2015.7.SPINE141306. 
WHO estimated that one-tenth of the world's adult population (4.7 billion, United Nations) were obese, further detailing that at least 2.8 million adults die each year as a result of comorbid conditions related to being overweight or obese. In addition, $44 \%$ of the diabetes burden, $23 \%$ of the ischemic heart disease burden, and between $7 \%$ and $41 \%$ of certain cancer burdens are attributable to being overweight or obese.

Increased BMI is a major risk factor for diseases such as musculoskeletal disorders, especially lumbar spine degenerative disc disease, which is the second highest cause of employment-related absences in the developed world, generating a massive economical world impact with no foreseen decline. Paradoxically, the role of obesity in degenerative lumbar disc disease is still considered controversial, and few studies to date have examined the possible relationship between the two, even though lumbar disc degeneration is the main cause of low-back pain. Research conducted over the past decade has led to a dramatic shift in the understanding of disc degeneration and its etiology. Previously, it was thought that heavy physical loading was the main risk factor, ${ }^{3}$ but recent research indicates that heredity plays the dominant role in disc degeneration. $1,2,9,13,14,32$

A high association between obesity and disc degeneration has been reported in both the juvenile and adult populations. ${ }^{30,31}$ Furthermore, it has been shown that spines from obese patients have a significantly greater prevalence of facet joint osteoarthritis..$^{15}$ Despite this link between degeneration and obesity, little is known about the relationship between obesity and spine biomechanics. The relationship between disc degeneration and spinal range of motion (ROM) has been studied both in living patients ${ }^{4}$ and in vitro, ${ }^{11,16,17,24,26,34}$ with most of these investigators reporting donor ages and sex, and some reporting bone mineral density (BMD). ${ }^{26}$ However, no previous investigators conducting in vitro studies have considered BMI as a possible factor affecting spine biomechanics. Thus, studies on the direct or indirect association between obesity and spine biomechanics are needed to further understand how obesity affects low-back pain.

The effect of overload in the lumbar motion segment has not yet been well defined. Theoretically, by Wolff's Law, lumbar motion segments from overweight individuals should have very good bone quality because bone under compression usually adapts and strengthens. ${ }^{10}$ However, the body may respond to overloading by inducing calcification or by stiffening the ligaments and disc area to impart bending stability to the motion segment.

The goal with this study was to determine if there are any biomechanical differences between cadaveric lumbar spine specimens from nonobese and obese donors. A second goal was to study the radiological differences between spines from these 2 groups using MR imaging.

\section{Methods}

Over a period of several years, our laboratory gathered data on the biomechanical flexibility of uninstrumented spines as a regular component of numerous other studies. For all of these studies, we tested the intact conditions of the spines before we tested them with various types of instrumentation. A total of 168 fresh frozen human cadaveric lumbar spine segments including L4-5 were obtained from local tissue banks. The donor histories were reviewed and parameters including age, sex, height, and weight of the donor at the time of death were documented for each case. There were 81 female and 87 male donors with a mean age of $53.1 \pm 12.1$ years. The specimens were carefully cleaned of muscle tissue, while all ligaments, joint capsules, and discs were kept intact. Dual-energy x-ray absorptiometry scans were obtained of the L-4 vertebra of each specimen to assess BMD. Plain film radiographs were taken, and histories were reviewed to ensure that no specimens had any of the following conditions: obvious flaws, metastatic disease, osteophytes, disc narrowing, or joint arthrosis.

To perform the biomechanical test, the sacrum was reinforced with household wood screws embedded in a block of fast-curing resin (Smooth-Cast 300Q, SmoothOn, Inc.), and attached to the base of the testing apparatus. The L-3 vertebra was also reinforced with household screws and embedded in resin in a cylindrical metal fixture for load application (Fig. 1).

The biomechanical characteristics of all specimens were determined in their native condition. An apparatus was used in which a system of cables and pulleys imparted nondestructive, nonconstraining torques in conjunction with a standard servohydraulic test system. ${ }^{6}$ With puremoment loading, the same load is distributed to each level of the spine, ensuring an equivalent comparison among all levels and among all specimens regardless of the distance from the point of loading. ${ }^{27}$ Maximum loads of $7.5 \mathrm{Nm}$ were applied in the appropriate anatomical axes to induce bending or twisting in each plane of motion: flexion and extension, left and right lateral bending, and left and right axial rotation. In each loading direction, 3 preconditioning cycles were applied at $7.5 \mathrm{Nm}$ for 60 seconds each, after which the specimen was allowed to rest at zero load for 60 seconds. During the data-collection cycle, loads were applied quasi-statically in $1.5-\mathrm{Nm}$ increments, with each incremental load held for 45 seconds to a maximum of $7.5 \mathrm{Nm}$.

After pure-moment flexibility testing, vertical compression was applied to 38 of the specimens ( 24 obese and 14 nonobese) using the piston on the servohydraulic apparatus. In each case, the specimen was placed on the loading frame below the piston and was moved anteroposteriorly and laterally to a position that eliminated the majority of rotational motion and allowed primarily vertical translation. A spherical end was used to apply load against the flat upper potting fixture of the specimen to ensure nonconstraining loading. An axial compression of $300 \mathrm{~N}$ was applied to the specimen quasi-statically in 50-N increments (45 seconds at each load).

Three-dimensional specimen motion in response to the applied loads during pure-moment and compression tests was determined using the Optotrak 3020 system (Northern Digital). This system measures stereophotogrammetrically the 3D displacement of infrared-emitting markers rigidly attached in a noncollinear arrangement to each vertebra on the ends of 4-cm surgical guidewires. 


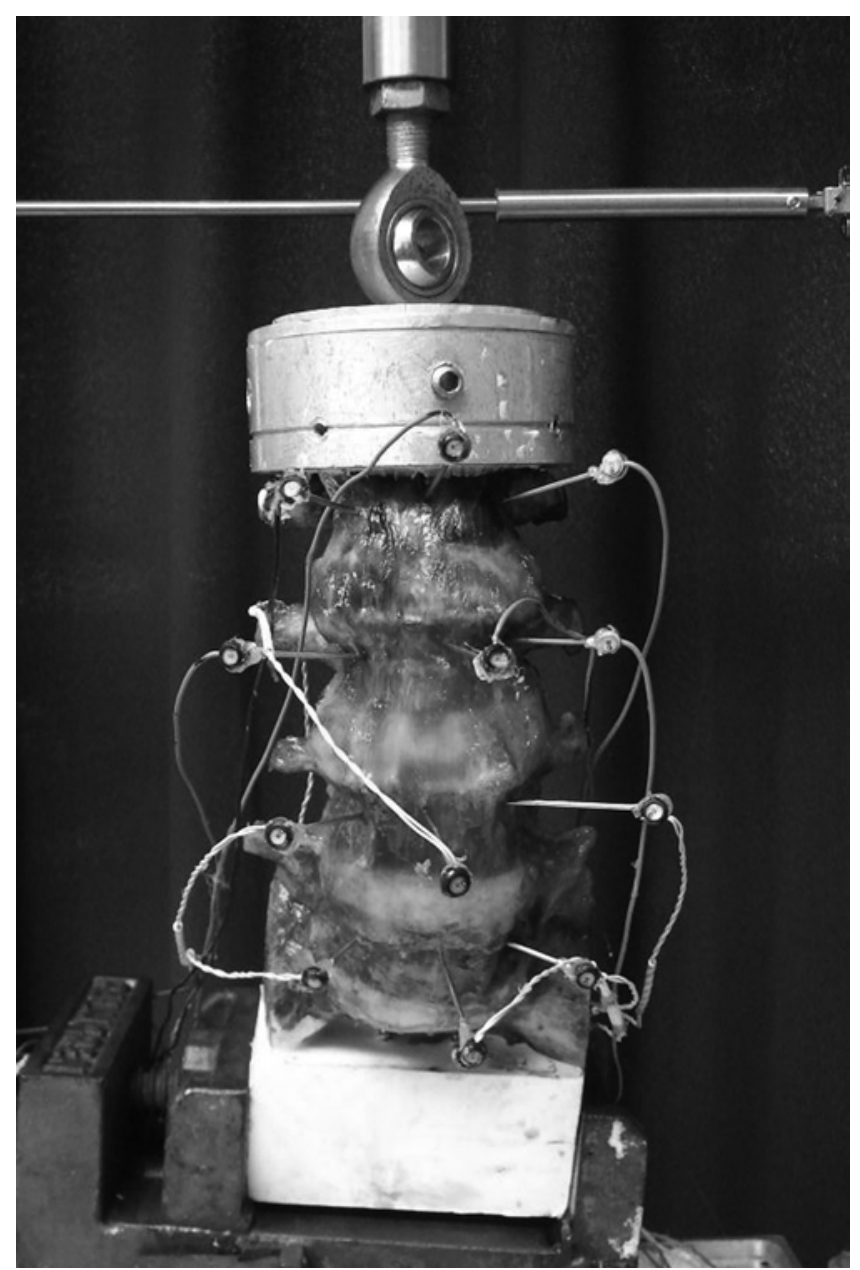

FIG. 1. Photograph of the testing apparatus for axial compressive loading. 3D displacement of each vertebra was determined using 3 infraredemitting markers rigidly attached in a noncollinear arrangement to each vertebra at the ends of 4-cm surgical guidewires.

Custom software converted the marker coordinates to angles about each of the anatomical axes in terms of the motion segment's own coordinate system. ${ }^{7}$ Spinal angles were calculated using a technique that provides appropriate results for describing 3D spinal motion. ${ }^{8}$ Translation was measured bilaterally as motion relative to L-5 of virtual landmarks located at the inferior surfaces of the left and right L-4 pedicle, where the nerve roots would exit.

From the raw load and displacement data, the mean angular ROM was quantified. For compressive testing, the mean interpedicular distance (L4-5) was quantified at 0 $\mathrm{N}$ and $300 \mathrm{~N}$.

MR images were obtained using a 3-T MR scanner (Philips) in our hospital's MR imaging research facility. Twelve cadaveric lumbar spine specimens ( 8 from obese and 4 from nonobese donors) were scanned using spine surface coils. The cadaveric spines were placed prone, and surfactants were added to the water to decrease bubbles and reduce artifact. Four lumbar spine specimens were suspended in a water bath for each scanning session for a total of 3 scan sessions and a total scan and processing time of approximately 6 hours.
Four series of images were obtained for each cadaveric spine. Sagittal T2-weighted, sagittal T1-weighted, sagittal T2-weighted inversion recovery, and axial T2-weighted MR images were analyzed by a neuroradiologist, and each cadaveric spine was evaluated for degenerative changes at the L3-4, L4-5, and L5-S disc levels. Specimens were graded for intervertebral disc degenerative changes at all lumbar levels according to the Pfirrmann classification system. ${ }^{28}$ Specimens were also graded for facet degeneration bilaterally using the Weishaupt classification system. ${ }^{36}$

The mean values of the ROM and vertical displacement at $300-\mathrm{N}$ axial compressive loading from obese (BMI $\geq$ $30)$ and nonobese (BMI < 30) groups for all specimens and for male or female subgroups were compared using 1-way ANOVA, followed by Holm-Šídák tests. Relationships between parameters were further analyzed using Pearson correlation tests. Multiple regression analysis was also performed to determine the relative importance of donor characteristics (sex, age, BMI, and BMD) in predicting the biomechanical behavior at L4-5 (mobility and axial compressive stiffness). Parameters from the radiological observations were analyzed using the Mann-Whitney rank test. Probability values $<0.05$ were considered significant.

\section{Results}

BMI data were available for 154 of the 168 specimens. Considering the entire study group $(n=168)$, there were no statistically significant differences between all male and all female groups in terms of age or BMD (Table 1, $p$ $>0.2$ ). For those with known BMI, the mean BMI in the female group $(n=72)$ was significantly greater than that in the male group $(n=82$ ) (Table $1, p=0.005)$. Further subdivision of groups into BMI $<30$ (52 males and 30 females) and $\mathrm{BMI} \geq 30$ (30 males and 42 females) did not result in any significant differences in mean age, BMD, or BMI between male and female groups in either BMI category (Table $1, \mathrm{p}>0.1)$. In the nonobese group (BMI $<30$, $\mathrm{n}=82), 16(20 \%)$ were from donors who were underweight (BMI < 18.5) at the time of death, $36(44 \%)$ were normal weight (BMI 18.5-24.9), and 30 (37\%) were overweight (BMI 25.0-29.9).

Table 2 presents the summary results for vertical displacement and ROM for all subgroups, and Table 3 summarizes the 1-way ANOVA results for subgroup comparisons. The mean vertical displacement at $300-\mathrm{N}$ axial compression was significantly less for the obese population and the obese female group compared with the nonobese population and nonobese females, respectively (Fig. $2, p<0.01$ ). Considering only the male population, the difference between obese and nonobese males was nonsignificant $(\mathrm{p}=0.304)$. Vertical displacement during axial compression tests $(0-300 \mathrm{~N})$ was $0.731 \pm 0.221 \mathrm{~mm}$ for the obese donor group and $1.097 \pm 0.570 \mathrm{~mm}$ for the nonobese group $(\mathrm{p}=0.008)$.

Based on the mean ROM, there were no significant differences among subgroups in terms of flexibility during flexion-extension or lateral bending (Fig. 3, p > 0.13), with the exception that the ROM during lateral bending was significantly less $(\mathrm{p}=0.045)$ for all males than for all females $\left(9.8^{\circ} \pm 2.6^{\circ}\right.$ vs $\left.10.6^{\circ} \pm 2.6^{\circ}\right)$. However, during 
TABLE 1. Breakdown of population and subgroups*

\begin{tabular}{ccccc}
\hline Variable & No. of Patients & Age $(\mathrm{yrs})$ & $\mathrm{BMl}\left(\mathrm{kg} / \mathrm{m}^{2}\right) \dagger$ & $\mathrm{BMD}\left(\mathrm{g} / \mathrm{cm}^{2}\right)$ \\
\hline Overall & & & & \\
\hline Total & 168 & $53.1 \pm 12.1$ & $32.2 \pm 13.2$ & $0.829 \pm 0.156$ \\
\hline Male & 87 & $54.1 \pm 11.4$ & $29.4 \pm 11.9$ & $0.830 \pm 0.145$ \\
\hline Female & 81 & $52.0 \pm 12.8$ & $35.4 \pm 14.0$ & $0.827 \pm 0.167$ \\
\hline p value (F vs M) & & 0.280 & 0.005 & 0.901 \\
\hline BMl <30 & & & $22.6 \pm 4.7$ & $0.808 \pm 0.146$ \\
\hline Total & 52 & $53.2 \pm 12.1$ & $22.7 \pm 4.8$ & $0.824 \pm 0.133$ \\
\hline Male & 30 & $53.6 \pm 12.2$ & $22.5 \pm 4.6$ & $0.781 \pm 0.164$ \\
\hline Female & & $52.7 \pm 12.1$ & 0.827 & 0.210 \\
\hline p value (F vs M) & 0.759 & & $0.855 \pm 0.161$ \\
\hline BMI $\geq 30$ & 72 & $52.5 \pm 12.2$ & $43.2 \pm 11.1$ & $0.841 \pm 0.160$ \\
\hline Total & 30 & $55.1 \pm 10.4$ & $41.0 \pm 11.5$ & $0.865 \pm 0.163$ \\
\hline Male & 42 & $50.6 \pm 13.2$ & $44.7 \pm 10.7$ & 0.553 \\
\hline Female & & 0.124 & 0.175 & \\
\hline p value (F vs M) & & & & \\
\hline
\end{tabular}

${ }^{*}$ Mean values are presented as the mean \pm SD. The value in boldface indicates statistical significance $(p<0.05)$.

$\dagger$ BMl unknown in 14 cases (8 females and 6 males).

axial rotation, a significant difference was noted between the segments from obese males and nonobese males $(\mathrm{p}=$ $0.018)$, with segments from nonobese males $\left(4.1^{\circ} \pm 1.9^{\circ}\right)$ being less mobile than those from obese males $\left(5.2^{\circ} \pm\right.$ $\left.2.3^{\circ}\right)$. There was no difference between segments from obese females and nonobese females during axial rotation $(\mathrm{p}=0.687)$ or segments from all obese versus all nonobese donors $(\mathrm{p}=0.061)$. Considering the nonobese population, the ROM during axial rotation was significantly greater for the female group $\left(5.4^{\circ} \pm 2.3^{\circ}\right)$ versus the male group $\left(4.1^{\circ} \pm 1.9^{\circ}\right)$ (Fig. $\left.3, p=0.009\right)$. The difference between the male and female groups among the obese population was not significant $(\mathrm{p}=0.892)$ during axial rotation but was

TABLE 2. Summary of results*

\begin{tabular}{ccrcc}
\hline & & \multicolumn{3}{c}{ ROM $\left(^{\circ}\right)$} \\
\cline { 3 - 5 } Variable & Disp $_{300 \mathrm{~N}}(\mathrm{~mm})$ & $\begin{array}{c}\text { Flexion- } \\
\text { Extension }\end{array}$ & $\begin{array}{c}\text { Lateral } \\
\text { Bending }\end{array}$ & $\begin{array}{c}\text { Axial } \\
\text { Rotation }\end{array}$ \\
\hline Overall & & & & \\
\hline Total & $0.866 \pm 0.420$ & $10.0 \pm 3.0$ & $10.2 \pm 2.6$ & $4.9 \pm 2.1$ \\
\hline Female & $0.856 \pm 0.494$ & $10.3 \pm 3.0$ & $10.6 \pm 2.6$ & $5.3 \pm 2.0$ \\
\hline Male & $0.875 \pm 0.354$ & $9.6 \pm 3.0$ & $9.8 \pm 2.6$ & $4.5 \pm 2.1$ \\
\hline BMI <30 & & & & \\
\hline Total & $1.097 \pm 0.570$ & $10.0 \pm 3.2$ & $10.1 \pm 2.7$ & $4.6 \pm 2.2$ \\
\hline Male & $0.967 \pm 0.464$ & $9.5 \pm 3.1$ & $9.8 \pm 2.7$ & $4.1 \pm 1.9$ \\
\hline Female & $1.332 \pm 0.719$ & $10.9 \pm 3.2$ & $10.6 \pm 2.3$ & $5.4 \pm 2.3$ \\
\hline BMI $\geq 30$ & & & & \\
\hline Total & $0.731 \pm 0.221$ & $9.9 \pm 2.8$ & $10.2 \pm 2.5$ & $5.2 \pm 2.0$ \\
\hline Male & $0.799 \pm 0.227$ & $10.0 \pm 3.0$ & $9.8 \pm 2.4$ & $5.2 \pm 2.3$ \\
\hline Female & $0.673 \pm 0.207$ & $9.8 \pm 2.7$ & $10.5 \pm 2.6$ & $5.2 \pm 1.8$ \\
\hline
\end{tabular}

Disp $_{300 \mathrm{~N}}=$ vertical displacement at $300-\mathrm{N}$ axial compression.

${ }^{*}$ Mean \pm SD. statistically significant $(\mathrm{p}=0.017)$ when all females $\left(5.3^{\circ} \pm\right.$ $\left.2.0^{\circ}\right)$ were compared with all males $\left(4.5^{\circ} \pm 2.1^{\circ}\right)$.

Table 4 presents the results of correlation analyses between BMI and vertical displacement and ROM. Correlation analyses showed that there was a significant relationship between BMI and resistance to compression during axial loading in the female population, with a tendency for the vertical displacement during loading to decrease with increased BMI (Fig. 4, R = -0.65, p = 0.004), i.e., specimens from obese female donors were stiffer than those from the nonobese group during axial compression. There was no such relationship in the male population (Fig. 4, R $=0.03, p=0.9)$. Similarly, there were significant correlations between the range of motion and BMI in the nonobese female population (Table 4) during flexion-extension $(R=-0.45, p=0.011)$ and lateral bending $(R=-0.37$, $\mathrm{p}=0.045)$, with mobility decreasing with increasing BMI. In contrast to 1-way ANOVA, which showed that there was a significant difference in the ROM during axial rota-

TABLE 3. Summary of $p$ values from 1-way ANOVA*

\begin{tabular}{lcccc}
\hline & & \multicolumn{3}{c}{ ROM } \\
\cline { 3 - 5 } Variable & Disp $_{300 \mathrm{~N}}$ & $\begin{array}{c}\text { Flexion- } \\
\text { Extension }\end{array}$ & $\begin{array}{c}\text { Lateral } \\
\text { Bending }\end{array}$ & $\begin{array}{c}\text { Axial } \\
\text { Roation }\end{array}$ \\
\hline Female vs male & & & & \\
\hline Total & 0.893 & 0.131 & $\mathbf{0 . 0 4 5}$ & $\mathbf{0 . 0 1 7}$ \\
\hline $\mathrm{BMl}<30$ & 0.267 & 0.053 & 0.186 & $\mathbf{0 . 0 0 9}$ \\
\hline $\mathrm{BMI} \geq 30$ & 0.168 & 0.822 & 0.269 & 0.892 \\
\hline $\mathrm{BMI}<30$ vs $\geq 30$ & & & & \\
\hline Total & $\mathbf{0 . 0 0 8}$ & 0.868 & 0.791 & 0.061 \\
\hline Female & $\mathbf{0 . 0 0 7}$ & 0.142 & 0.841 & 0.687 \\
\hline Male & 0.304 & 0.457 & 0.973 & $\mathbf{0 . 0 1 8}$ \\
\hline * Values in boldface indicate statistical significance $(\mathrm{p}<0.05)$. &
\end{tabular}

${ }^{*}$ Values in boldface indicate statistical significance $(p<0.05)$. 


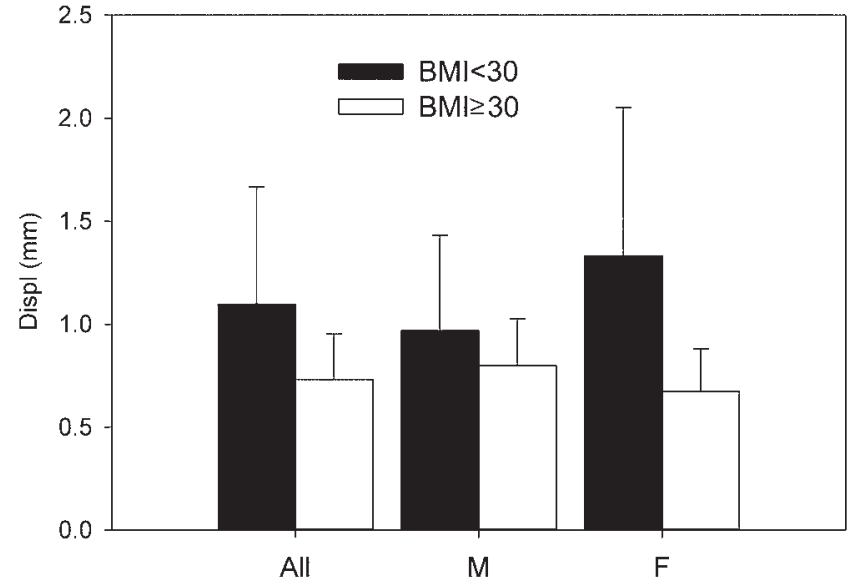

FIG. 2. Mean vertical L4-5 displacement (Displ) ( \pm 1 SD) during $300-\mathrm{N}$ axial compression for different subgroups.

tion between the obese and nonobese male groups (Fig. 3 and Table 3; $\mathrm{p}=0.018$ ), there were no significant correlations between $\mathrm{BMI}$ and ROM during axial rotation in any groups (Table 4; $\mathrm{R}<0.2, \mathrm{p}>0.1$ ).

Disregarding BMI, there were significant and positive correlations $(\mathrm{R}>0.49, \mathrm{p}<0.02)$ between vertical displacement during axial compression and ROM in all groups and in all directions of movement (flexion-extension, lateral bending, and axial rotation), i.e., the spine segments were less stiff during axial compression with increasing ROM. The most positive relationship was seen during axial rotation (Fig. 5; $\mathrm{R}=0.7, \mathrm{p}<0.001$ ).

Based on multiple linear regression analysis and using sex, age, BMD, and BMI as independent variables, all parameters except for BMI were significant in predicting some component of biomechanical behavior at L4-5 (Table 5 and Fig. 6). Mobility significantly increased with age, but only during axial rotation $(\mathrm{p}<0.001$; Fig. 7 and Table $5)$. Sex also predicted axial rotation mobility $(p=0.008$; Table 5) with spines in the nonobese male group having significantly less flexibility than those from the nonobese female group during axial rotation (Fig. 3 and Tables 2 and 3). Also, based on multiple regression analysis, BMD was an important parameter in predicting axial compressive stiffness and mobility during flexion-extension (Table $5, \mathrm{p}<0.01)$.

Radiological analysis by a neuroradiologist showed that all $12(100 \%)$ disc levels from the nonobese group $(n=4$ spinal segments) had no or mild disc degenerative changes. Seventeen of the 22 disc levels $(77 \%)$ in the obese group (n $=8$ spinal segments) had no or mild degenerative changes, and 5 of the 22 levels (23\%) had moderate to severe degenerative disc disease (Fig. 8). Thus, the specimens from the nonobese group showed less disc degeneration than those from obese donors, but the difference was not statistically significant $(\mathrm{p}=0.09)$.

Based on the Weishaupt classification system, ${ }^{36}$ the mean grade representing facet degenerative changes in the normal group was 0.08 compared with 1.05 in the obese group $(\mathrm{p}=0.002)$. There were no bony reactive changes in the vertebral endplates in the normal group $(0 \%$ in 12

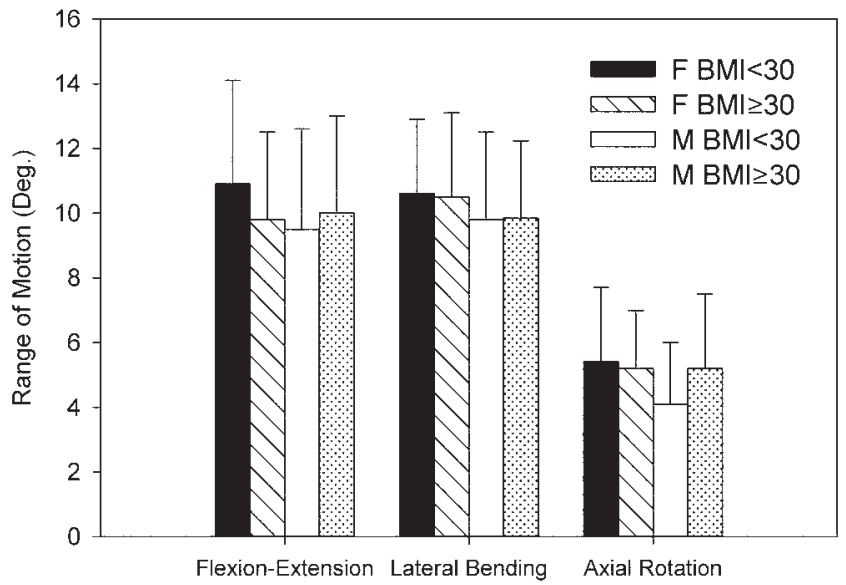

FIG. 3. Mean ROM $( \pm 1 \mathrm{SD})$ during different directions of loading for obese $(\mathrm{BMI} \geq 30)$ and nonobese $(\mathrm{BMI}<30)$ subgroups by sex.

motion segments), and there were endplate changes in 2 of 22 motion segments $(9 \%)$ in the obese group $(\mathrm{p}=0.22)$. Analysis of the MR images revealed zero disc herniations at 12 levels $(0 \%)$ in the normal weight group, compared with 5 disc herniations at 22 levels $(23 \%)$ in the obese group $(\mathrm{p}=0.09)$.

\section{Discussion}

From the 154 donors with known BMI at the time of death, $47 \%$ of the spines in this study were from donors considered to be obese, $19 \%$ were overweight, $23 \%$ were normal weight, and $10 \%$ were underweight. According to recent NHANES (National Health and Nutrition Examination Survey) data, $36 \%$ of the US adult population is considered obese, $33 \%$ overweight, $29 \%$ normal, and $2 \%$ underweight. ${ }^{25}$ The different distribution in our study population is most likely due to the advanced mean age of the donors versus the mean age of US adults. In the current study, and considering the entire study group (males and females and the entire range of $\mathrm{BMI}$ ), there was no correlation between resistance to compression (i.e., axial stiffness) and age (range $18-73$ years, with mean of $53.1 \pm 12.1$ years) $(\mathrm{R}=0.187, \mathrm{p}=0.261)$. Upon separation into subgroups, we found that segments were stiffer in the obese versus nonobese groups in the female-only and femaleplus-male subgroups, but not the male-only subgroup. This finding is in contrast to what has been reported by Stemper el al., ${ }^{33}$ who studied the biomechanical properties of human thoracic spine disc segments and reported a trend for greater stiffness in specimens from male donors. Sex differences related to spine biomechanics are well documented. ${ }^{12,22,23,33,37,39}$ Gilsanz et al. ${ }^{12}$ reported a $25 \%$ smaller mean cross-sectional area in female versus male lumbar vertebral bodies $\left(8.22 \pm 1.09 \mathrm{~cm}^{2}\right.$ vs 10.98 $\left.\pm 1.25 \mathrm{~cm}^{2}, \mathrm{p}<0.001\right)$ and volumes $\left(22.42 \pm 2.4 \mathrm{~cm}^{3}\right.$ vs $\left.30.86 \pm 2.6 \mathrm{~cm}^{3}, \mathrm{p}<0.001\right)$, estimating that the mechanical stress within the vertebral body to be $30 \%-40 \%$ higher in women than men for equivalent loads. They noted that bone densities did not differ by sex. In 2000, Marras et al. ${ }^{22}$ studied the effects of psychosocial stress on lumbar 
TABLE 4. $R$ values and $p$ values (in parentheses) from Pearson correlation analyses for BMI versus Disp $p_{300 N}$ and ROM*

\begin{tabular}{|c|c|c|c|c|}
\hline \multirow[b]{2}{*}{ Variable } & \multirow[b]{2}{*}{ Disp $_{300 N}$} & \multicolumn{3}{|c|}{ ROM } \\
\hline & & Flexion-Extension & Lateral Bending & Axial Rotation \\
\hline \multicolumn{5}{|c|}{ Overall BMI } \\
\hline Total & $-0.30(0.067)$ & $-0.13(0.114)$ & $0.03(0.732)$ & $0.11(0.179)$ \\
\hline Male & $0.03(0.903)$ & $0.06(0.584)$ & $0.07(0.541)$ & $0.16(0.149)$ \\
\hline Female & $-0.65(0.004)$ & $-0.38(0.001)$ & $-0.07(0.536)$ & $-0.01(0.885)$ \\
\hline \multicolumn{5}{|l|}{$\mathrm{BMI}<30$} \\
\hline Total & $-0.08(0.786)$ & $-0.25(0.022)$ & $-0.25(0.042)$ & $-0.04(0.730)$ \\
\hline Male & $0.30(0.400)$ & $-0.14(0.314)$ & $-0.15(0.296)$ & $-0.08(0.560)$ \\
\hline Female & $-0.54(0.353)$ & $-0.45(0.011)$ & $-0.37(0.045)$ & $0.04(0.876)$ \\
\hline \multicolumn{5}{|l|}{$\mathrm{BMI} \geq 30$} \\
\hline Total & $0.04(0.840)$ & $-0.18(0.126)$ & $0.15(0.222)$ & $-0.00(0.981)$ \\
\hline Male & $0.49(0.125)$ & $0.11(0.577)$ & $0.33(0.077)$ & $-0.04(0.841)$ \\
\hline Female & $-0.58(0.036)$ & $-0.42(0.006)$ & $-0.01(0.942)$ & $0.04(0.818)$ \\
\hline
\end{tabular}

* Values in boldface indicate statistically significant correlations $(p<0.05)$.

spine loading in young subjects (19-31 years) using electromyography, and reported that women's anteroposterior shear forces increased in response to stress, while men's decreased. In 2003, and again using electromyography, Marras et al. ${ }^{23}$ reported sex influences during complex lifting in the workplace. They concluded that muscle coactivity differences combined with unequal body masses account for the spine-loading sex differences, and that women are not just proportionally scaled down versions of men. Women relied more on hip motion and used more extensor muscle activity than men.

Using spines from a skeletal collection including $39 \mathrm{fe}-$ males and 37 males, Zukowski et al. studied the influence of sex, age, and BMI on the degeneration of the lumbar spine. ${ }^{39}$ They found that osteophyte severity in the lumbar spine increased with age for both sexes and severity increased with BMI for females, but not for males; they concluded that this is evidence for different sex biomechanical processes influencing osteophyte development.

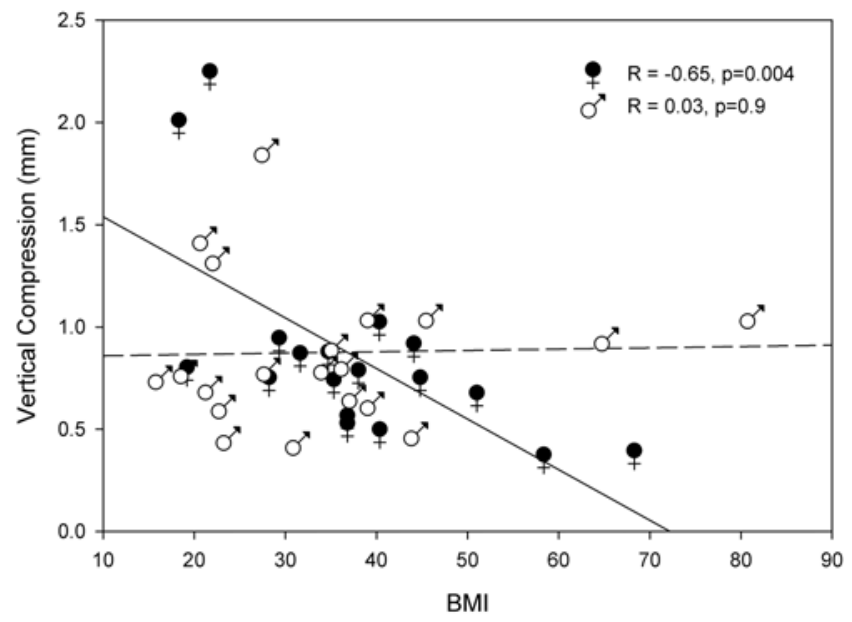

FIG. 4. Vertical compression versus BMI for male and female subgroups. R value for all segments: $-0.3(p=0.067)$.
As mentioned earlier, the donor specimens included in our study were screened for spine disease and deformity, including severe osteophytes and degenerative disc disease. Therefore, the information we are reporting regarding BMI and its effect on biomechanics represents trends for a population not including those with obvious developed advanced spine disease. Also, the BMI data are based on the donor weights at the time of death. We do not know how long the donors were obese (or not obese) prior to the time of death, or whether there were any substantial weight fluctuations just before death. An additional limitation is that we do not have records of whether the donors were symptomatic. An interesting study would be to see how obesity affects disc degeneration and spinal instability over time. However, such a study would necessitate historic donor BMI data, which were not available for the current study.

Using a comparatively large group of specimens (203

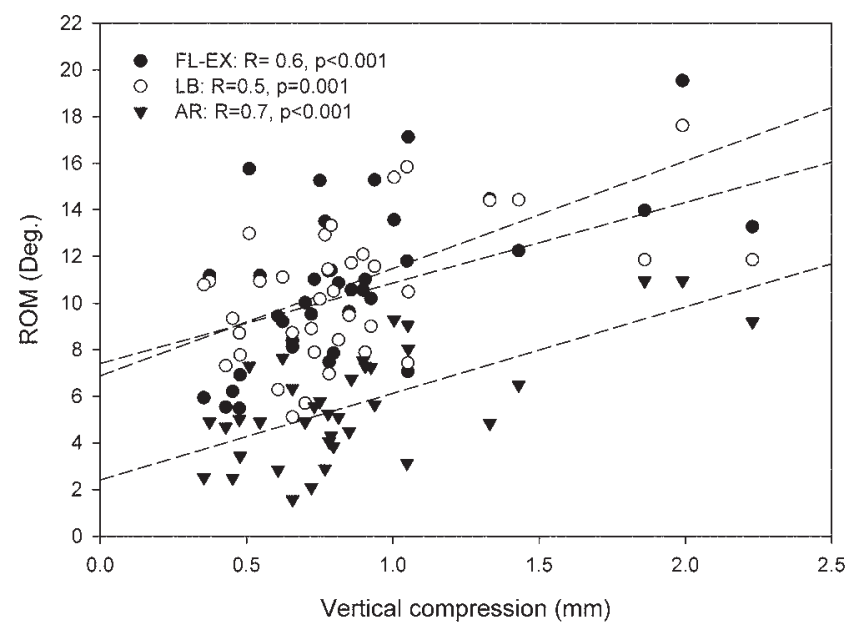

FIG. 5. Range of motion versus vertical displacement during axial compression (both male and female). AR = axial rotation; FL-EX = flexionextension; LB = lateral bending. 
TABLE 5. $p$ values from multiple linear regression analyses using sex, age, BMI, and BMD as independent variables to predict biomechanical parameters considering the entire study population $(n=168)^{*}$

\begin{tabular}{lcccc}
\hline \multicolumn{1}{c}{ Parameter } & Sex & Age & BMI & BMD \\
\hline Disp $_{300 \mathrm{~N}}$ & 0.740 & 0.746 & 0.055 & $\mathbf{0 . 0 0 6}$ \\
\hline ROM & & & & \\
\hline Flexion-extension & 0.128 & 0.403 & 0.145 & $\mathbf{0 . 0 0 7}$ \\
\hline Lateral bending & 0.179 & 0.072 & 0.635 & 0.060 \\
\hline Axial rotation & $\mathbf{0 . 0 0 8}$ & $<0.001$ & 0.294 & 0.825 \\
\hline
\end{tabular}

* Values in boldface indicate statistical significance $(p<0.05)$. Biomechanical parameters were vertical displacement at $300-\mathrm{N}$ axial compression and ROM during flexion-extension, lateral bending, and axial rotation.

spine segments from 111 donors, age 19-99 years, 45 female, 61 male, and 5 with unknown sex), Kettler et al..$^{16}$ looked at the influence of disc degeneration on the lumbar spine stability using flexibility data (7.5-Nm pure-moment multidirectional loading) and radiographs. Using a grading scale for disc degeneration related to height loss, osteophytes, and sclerosis, combined with ROM, they concluded that early stages of intervertebral disc degeneration do not cause spinal instability, but increased disc degeneration leads to decreased ROM during flexion-extension and lateral bending, and increased ROM during axial rotation (as seen in our study). In addition to Kettler and colleagues' large study, the effects of disc degeneration on biomechanics in terms of ROM in the lumbar spine has been the focus of a number of other in vitro studies. ${ }^{11,17,24,26,34}$ An increasing amount of ROM during axial rotation with an increased degree of degeneration has been reported in at least 4 other studies, $16,17,24,26$ while a decreased amount of ROM during lateral bending has been reported in 3,16,24,26 and a decreased ROM during flexion-extension in $2 .{ }^{16,24}$ Although most of these studies include reported donor ages and some data analyzed according to sex ${ }^{11}$ and $\mathrm{BMD},{ }^{26}$ none have included BMI as a possible contributing factor affecting the ROM in the lumbar spine. Our data suggest that obesity does af-

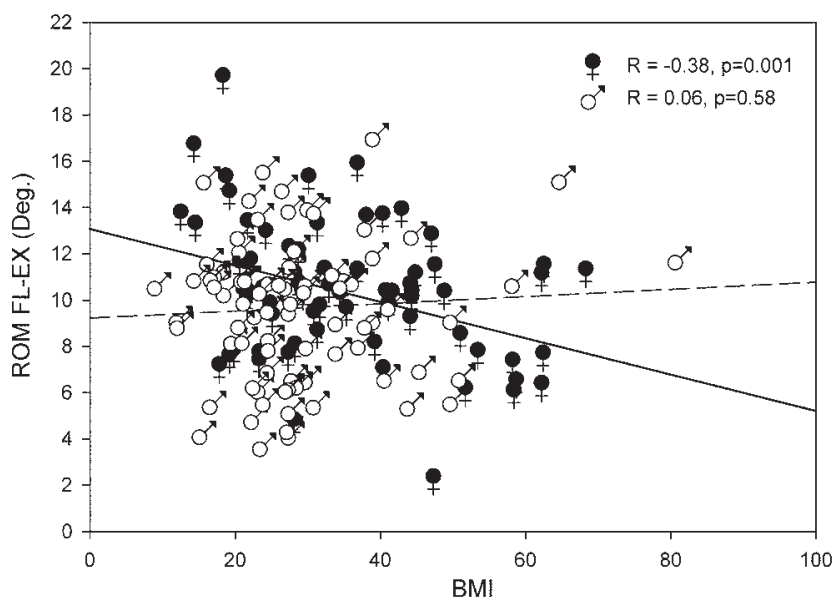

FIG. 6. Range of motion during flexion-extension versus $\mathrm{BMI}$, for male and female subgroups. $R$ value for all segments $=-0.13(p=0.114)$.

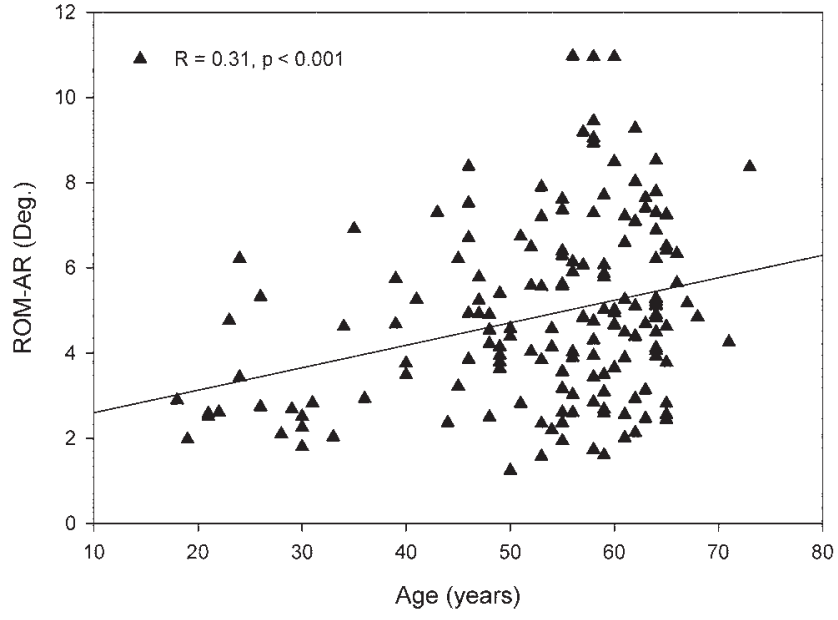

FIG. 7. Range of motion during axial rotation versus age (both male and female).

fect spine mobility, but only during axial rotation (Fig. 3). Possible reasons for the different biomechanical behaviors during axial rotation versus lateral bending and flexion-extension have been hypothesized by Kettler et al. ${ }^{16}$ as being 3 -fold. First of all, degenerative discs have been shown to have fissures and delaminations ${ }^{17}$ that cause the disc to not be able to resist shear loads as effectively as healthy discs. During flexion-extension and lateral bending, the loads are mostly compressive and tensile, and a disc with fissures and de-laminations is assumed to be less affected by these during compression and tension. Second, the facet joints are assumed to restrict axial rotation depending on their align-

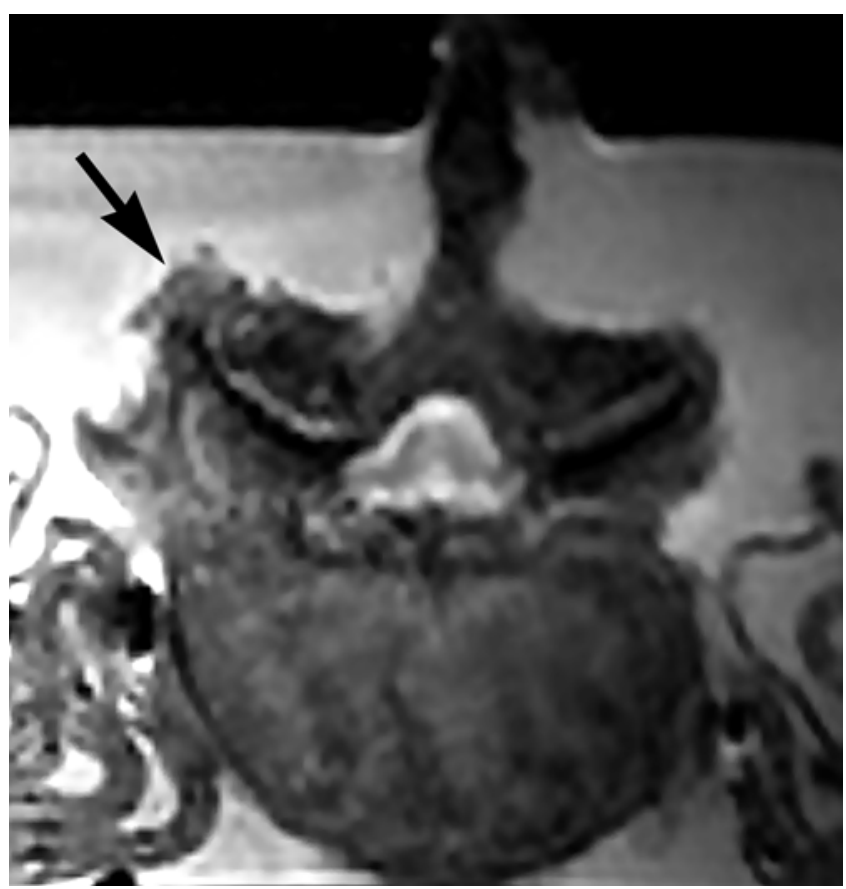

FIG. 8. Axial MR image showing greater facet degeneration on the right side (arrow). 
ment. With increased degenerative kyphosis, restriction to movement lessens during axial rotation and thus instability increases. The last mentioned possible reason is that stability during axial rotation may be affected by degenerative loss of cartilage in the facet joints. Oxland et al. ${ }^{26}$ looked at the effects of BMD on intervertebral disc degeneration in the lumbar spine using spinal flexibility and reported that BMD in moderately degenerated discs was significantly lower than at other levels of disc degeneration. Furthermore, there was a negative association between BMD and ROM during lateral bending and flexion-extension, but no relationship during axial rotation. This is supported by the findings in our study, where we showed that BMD was a significant factor in predicting ROM during flexion-extension $(\mathrm{p}=0.007)$ and marginal during lateral bending $(\mathrm{p}=$ $0.06)$, but not during axial rotation ( $\mathrm{p}=0.825)$. In our study, we found that there was a marginally significant correlation between BMD and BMI in the female group $(R=0.23$, $p$ $=0.055)$, but no correlation in the male group $(\mathrm{R}=-0.04$, $\mathrm{p}=0.666$ ).

There are only a few in vivo studies focusing on spine degeneration and the effects on spine biomechanics. Bible et al. ${ }^{4}$ quantified lumbar spinal segmental ROM in living subjects using flexion-extension radiographs of 258 patients (137 females and 121 males, 18-92 years). They looked at segmental ROM and degeneration in terms of the Kellgren score, and found a significant negative association between age and ROM during flexion-extension. In comparison, in our in vitro study, the relationship between age and ROM was only significant during axial rotation, and the association was positive (Fig. 7). Bible et al. ${ }^{4}$ also reported that BMI had a significant negative association with ROM during flexion-extension. This is similar to what we found in our in vitro study, but only in the female group (Fig. 6).

Although the association between obesity and lumbar disc degeneration, and therefore low-back pain, has been studied, ${ }^{18-20}$ a clear relationship has yet to be defined. One theory is that excessive mechanical loading caused by heavy weight disrupts the disc structures and precipitates a cascade of cell-mediated responses, leading to further disruption. ${ }^{1}$ Surprisingly, no other previous in vitro study has focused on the biomechanical behavior of the intact lumbar disc in terms of degeneration and the relationship to mobility during flexibility loading, and considering the response to axial compressive loads. Based on our findings, obesity seems to affect both flexibility and compressive stiffness, with significant sex differences.

Obese and morbidly obese patients have multiple comorbidities. The spinal surgeon should be prepared to encounter perioperative complexities. In addition, the rate of postoperative complications is high in these patients. ${ }^{35}$ Obesity is the main preventable risk factor for large joint osteoarthritis, ${ }^{29}$ and it has been proven that obesity greatly increases ground reaction forces during walking by applying more stress on the large joints. ${ }^{5}$ Facet joint degeneration has been described as contributing to persistent or chronic low-back pain. It may account for $15 \%-45 \%$ of low-back pain, with facet joint-mediated pain being a common occurrence in obese patients. ${ }^{21}$ Because it has been reported that increased levels of BMI $(>25)$ increases the risk of lumbar disc degeneration, ${ }^{20}$ we did a comparative radio- logical analysis between spinal segments from obese and nonobese donors. Our most important finding was that the obese donor group exhibited a significantly greater degree of facet degeneration compared with the nonobese group. This result may be related to the larger compressive axial loads that the facets in obese patients are subjected to. A previous study has shown a tendency for obese patients to have disc herniations..$^{20}$ In our study, we found a trend for specimens in the obese donor group to have more disc herniations than in the nonobese group. However, the difference was not statistically significant, perhaps because the sample was not large enough. Further radiological studies, including better control of the length of time of obesity, are needed.

\section{Conclusions}

Based on flexibility and compression tests, lumbar spinal segments from obese versus nonobese donors seem to behave differently, biomechanically, during axial rotation and compression, with coinciding sex differences. Radiological analysis showed that there was a significantly greater amount of facet degeneration and a trend for an increased amount of disc herniations in the spines from the obese group.

\section{References}

1. Adams MA, Roughley PJ: What is intervertebral disc degeneration, and what causes it? Spine (Phila Pa 1976) 31:21512161, 2006

2. Battié MC, Haynor DR, Fisher LD, Gill K, Gibbons LE, Videman T: Similarities in degenerative findings on magnetic resonance images of the lumbar spines of identical twins. J

Bone Joint Surg Am 77:1662-1670, 1995

3. Battié MC, Videman T, Parent E: Lumbar disc degeneration: epidemiology and genetic influences. Spine (Phila Pa 1976) 29:2679-2690, 2004

4. Bible JE, Simpson AK, Emerson JW, Biswas D, Grauer JN: Quantifying the effects of degeneration and other patient factors on lumbar segmental range of motion using multivariate analysis. Spine (Phila Pa 1976) 33:1793-1799, 2008

5. Browning RC, Kram R: Effects of obesity on the biomechanics of walking at different speeds. Med Sci Sports Exerc 39:1632-1641, 2007

6. Crawford NR, Brantley AG, Dickman CA, Koeneman EJ: An apparatus for applying pure nonconstraining moments to spine segments in vitro. Spine (Phila Pa 1976) 20:20972100, 1995

7. Crawford NR, Dickman CA: Construction of local vertebral coordinate systems using a digitizing probe. Technical note. Spine (Phila Pa 1976) 22:559-563, 1997

8. Crawford NR, Yamaguchi GT, Dickman CA: A new technique for determining 3-D joint angles: the tilt/twist method. Clin Biomech (Bristol, Avon) 14:153-165, 1999

9. Duance VC, Crean JK, Sims TJ, Avery N, Smith S, Menage J, et al: Changes in collagen cross-linking in degenerative disc disease and scoliosis. Spine (Phila Pa 1976) 23:2545-2551, 1998

10. Frost HM: Skeletal structural adaptations to mechanical usage (SATMU): 2. Redefining Wolff's law: the remodeling problem. Anat Rec 226:414-422, 1990

11. Fujiwara A, Lim TH, An HS, Tanaka N, Jeon CH, Andersson $\mathrm{GB}$, et al: The effect of disc degeneration and facet joint osteoarthritis on the segmental flexibility of the lumbar spine. Spine (Phila Pa 1976) 25:3036-3044, 2000 
12. Gilsanz V, Boechat MI, Gilsanz R, Loro ML, Roe TF, Goodman WG: Gender differences in vertebral sizes in adults: biomechanical implications. Radiology 190:678-682, 1994

13. Gruber HE, Hanley EN Jr: Ultrastructure of the human intervertebral disc during aging and degeneration: comparison of surgical and control specimens. Spine (Phila Pa 1976) 27:798-805, 2002

14. Kalb S, Martirosyan NL, Kalani MY, Broc GG, Theodore N: Genetics of the degenerated intervertebral disc. World Neurosurg 77:491-501, 2012

15. Kalichman L, Guermazi A, Li L, Hunter DJ: Association between age, sex, BMI and CT-evaluated spinal degeneration features. J Back Musculoskeletal Rehabil 22:189-195, 2009

16. Kettler A, Rohlmann F, Ring C, Mack C, Wilke HJ: Do early stages of lumbar intervertebral disc degeneration really cause instability? Evaluation of an in vitro database. Eur Spine J 20:578-584, 2011

17. Krismer M, Haid C, Behensky H, Kapfinger P, Landauer F, Rachbauer F: Motion in lumbar functional spine units during side bending and axial rotation moments depending on the degree of degeneration. Spine (Phila Pa 1976) 25:20202027,2000

18. Leboeuf-Yde C: Body weight and low back pain. A systematic literature review of 56 journal articles reporting on 65 epidemiologic studies. Spine (Phila Pa 1976) 25:226-237, 2000

19. Leboeuf-Yde C, Kyvik KO, Bruun NH: Low back pain and lifestyle. Part II-Obesity. Information from a populationbased sample of 29,424 twin subjects. Spine (Phila Pa 1976) 24:779-783, discussion 783-784, 1999

20. Liuke M, Solovieva S, Lamminen A, Luoma K, Leino-Arjas P, Luukkonen R, et al: Disc degeneration of the lumbar spine in relation to overweight. Int J Obes 29:903-908, 2005

21. Manchikanti L, Pampati V, Singh V, Beyer C, Damron K, Fellows B: Evaluation of the role of facet joints in persistent low back pain in obesity: a controlled, prospective, comparative evaluation. Pain Physician 4:266-272, 2001

22. Marras WS, Davis KG, Heaney CA, Maronitis AB, Allread WG: The influence of psychosocial stress, gender, and personality on mechanical loading of the lumbar spine. Spine (Phila Pa 1976) 25:3045-3054, 2000

23. Marras WS, Davis KG, Jorgensen M: Gender influences on spine loads during complex lifting. Spine J 3:93-99, 2003

24. Mimura M, Panjabi MM, Oxland TR, Crisco JJ, Yamamoto I, Vasavada A: Disc degeneration affects the multidirectional flexibility of the lumbar spine. Spine (Phila Pa 1976) 19:1371-1380, 1994

25. National Center for Health Statistics: Health, United States, 2013: With Special Feature on Prescription Drugs. Hyattsville, MD: National Center for Health Statistics, 2014

26. Oxland TR, Lund T, Jost B, Cripton P, Lippuner K, Jaeger $\mathrm{P}$, et al: The relative importance of vertebral bone density and disc degeneration in spinal flexibility and interbody implant performance. An in vitro study. Spine (Phila Pa 1976) 21:2558-2569, 1996

27. Panjabi MM, Cholewicki J, Nibu K, Grauer J, Babat LB, Dvorak J: Critical load of the human cervical spine: an in vitro experimental study. Clin Biomech (Bristol, Avon) 13:11-17, 1998

28. Pfirrmann CW, Metzdorf A, Zanetti M, Hodler J, Boos N: Magnetic resonance classification of lumbar intervertebral disc degeneration. Spine (Phila Pa 1976) 26:1873-1878, 2001

29. Powell A, Teichtahl AJ, Wluka AE, Cicuttini FM: Obesity: a preventable risk factor for large joint osteoarthritis which may act through biomechanical factors. Br J Sports Med 39:4-5, 2005

30. Samartzis D, Karppinen J, Chan D, Luk KD, Cheung KM: The association of lumbar intervertebral disc degeneration on magnetic resonance imaging with body mass index in overweight and obese adults: a population-based study. Arthritis Rheum 64:1488-1496, 2012

31. Samartzis D, Karppinen J, Mok F, Fong DY, Luk KD, Cheung KM: A population-based study of juvenile disc degeneration and its association with overweight and obesity, low back pain, and diminished functional status. J Bone Joint Surg Am 93:662-670, 2011

32. Sambrook PN, MacGregor AJ, Spector TD: Genetic influences on cervical and lumbar disc degeneration: a magnetic resonance imaging study in twins. Arthritis Rheum 42:366-372, 1999

33. Stemper BD, Board D, Yoganandan N, Wolfla CE: Biomechanical properties of human thoracic spine disc segments. J Craniovertebr Junction Spine 1:18-22, 2010

34. Tanaka N, An HS, Lim TH, Fujiwara A, Jeon CH, Haughton VM: The relationship between disc degeneration and flexibility of the lumbar spine. Spine J 1:47-56, 2001

35. Vaidya R, Carp J, Bartol S, Ouellette N, Lee S, Sethi A: Lumbar spine fusion in obese and morbidly obese patients. Spine (Phila Pa 1976) 34:495-500, 2009

36. Weishaupt D, Zanetti M, Boos N, Hodler J: MR imaging and CT in osteoarthritis of the lumbar facet joints. Skeletal Radiol 28:215-219, 1999

37. Wilke HJ, Zanker D, Wolfram U: Internal morphology of human facet joints: comparing cervical and lumbar spine with regard to age, gender and the vertebral core. J Anat 220:233-241, 2012

38. World Health Organization: Obesity and overweight. Fact Sheet No. 113. (http://www.who.int/mediacentre/factsheets/ fs311/en/) [Accessed October 6, 2015]

39. Zukowski LA, Falsetti AB, Tillman MD: The influence of sex, age and BMI on the degeneration of the lumbar spine. $\mathbf{J}$ Anat 220:57-66, 2012

\section{Disclosures}

Drs. Crawford and Theodore report that they have ownership of Excelsius Surgical, LLC.

\section{Author Contributions}

Conception and design: Crawford, Rodriguez-Martinez, PerezOrribo, Theodore. Acquisition of data: Rodriguez-Martinez, Perez-Orribo, Kalb, Reyes, Newcomb. Analysis and interpretation of data: Crawford, Rodriguez-Martinez, Hughes, Newcomb. Drafting the article: Rodriguez-Martinez, Kalb, Newcomb. Critically revising the article: Crawford, Rodriguez-Martinez, PerezOrribo, Kalb, Newcomb. Reviewed submitted version of manuscript: Crawford, Rodriguez-Martinez, Reyes, Newcomb, Hughes . Approved the final version of the manuscript on behalf of all authors: Crawford. Statistical analysis: Crawford, Newcomb, Hughes. Administrative/technical/material support: Crawford, Reyes, Hughes. Study supervision: Crawford, Reyes, Theodore.

\section{Correspondence}

Neil R. Crawford, c/o Neuroscience Publications, Barrow Neurological Institute, St. Joseph's Hospital and Medical Center, 350 W. Thomas Rd., Phoenix, AZ 85013.email: neuropub@ dignityhealth.org. 